\title{
Effect of Gum arabic on distribution behavior of nanocellulose fillers in starch film
}

\author{
Nadanathangam Vigneshwaran · L. Ammayappan • \\ Qingrong Huang
}

Received: 26 May 2011 / Accepted: 29 July 2011 / Published online: 24 August 2011

(C) The Author(s) 2011. This article is published with open access at Springerlink.com

\begin{abstract}
Uniform distribution of nanofillers in polymer matrix is posing a major challenge in exploiting the full potential of nanomaterials. Various fillers are being evaluated to improve the performance of biopolymer films like starch. In this work, nanocellulose is used as fillers to increase the performance characteristics of starch film. Due to high surface energy and hydrophilic nature of nanocellulose, they tend to aggregate during the film forming process. To circumvent this problem, Gum arabic (GA) was added to distribute the nanocellulose uniformly. GA helps in reduction of surface energy (as analyzed by contact angle) and thus facilitates the uniform distribution of nanocellulose (as demonstrated through polarized light microscopy). Nanocellulose as filler improved the tensile strength of starch film by 2.5 times while that of uniformly distributed nanocellulose by 3.5 times. Moreover, while nanocellulose as such could reduce the water vapor permeability of starch film by 1.4 times, uniformly distributed nanocellulose reduced it by 2 times proving the importance of GA. Starch film filled with nanocellulose and GA will be
\end{abstract}

N. Vigneshwaran ( ()

Chemical and Biochemical Processing Division,

Nanotechnology Research Group, Central Institute for Research

on Cotton Technology, Adenwala Road, Matunga,

Mumbai 400019, India

e-mail:nvw75@yahoo.com

L. Ammayappan

Division of Textile Manufacture and Textile Chemistry,

Central Sheep and Wool Research Institute, Avikanagar,

Jaipur 304501, India

Q. Huang

Department of Food Science, Cook College Rutgers University, New Brunswick, NJ 08901-8520, USA a $100 \%$ biopolymer-based system having potential demand in eco-friendly applications.

Keywords Atomic force microscopy - Gum arabic . Nanocellulose - Nanocomposites · Polarized microscopy · Surface energy

\section{Introduction}

Synthetic polymers, mostly petroleum-based, are used as packaging materials essentially due to their excellent thermo-mechanical properties and cheap availability. But their recalcitrant nature in environment poses a major threat compelling us to look for biopolymers. Starch is one of the most promising candidates for future composite materials because of their low cost, renewable nature, biodegradability and thermoplastic behavior (Mali et al. 2005a). The successful use of starch films depends on their mechanical and permeability properties (Arvanitoyannis 1999). The major problem with plasticized starch is its increased permeability to water vapor/oxygen and low strength. Starch owes much of its functionalities to its major components, amylose and amylopectin and their physical organization into granular structure (French 1984). To reinforce the starch matrix, nanocellulose prepared by acid hydrolysis is being used to improve the mechanical and functional properties (Teixeira et al. 2009; Chen et al. 2009; Wenjuan 2011). In these processes, the acid hydrolysis introduces bulky sulfate groups that help in uniform dispersion during composite formation. Even at low levels, the sulfate groups caused a significant decrease in degradation temperatures and an increase in char fraction confirming that the sulfate groups act as flame retardants (Roman and Winter 2004). But, the problem arises in 
biodegradability and hence nanocellulose without surface modification is essential for $100 \%$ eco-friendly biodegradable polymer composites.

Gum arabic (GA) is natural polysaccharide derived from the exudates of Acacia species. It is a complex branched hetero-polyelectrolyte with a backbone of 1,3-linked $\beta$-galactopyranose units and side chains of 1,6-linked galactopyranose units terminating in glucuronic acid or 4-O-methylglucuronic acid residues (Dickinson 2003). The emulsifying activity of GA is mostly due to its protein content and to trace levels of lipids (Al-Assaf et al. 2009). Commercially, GA is being used as stabilizer, thickening agent and hydrocolloid emulsifier. Recently, the use of GA has been extended to nanotechnology due to its stabilizing nature of nanostructures; it has been probed for the coating over iron oxide (Roque et al. 2009) and gold (Kannan et al. 2006) nanoparticles.

The reinforcing effect of any filler in polymer matrix is determined by the interface, aspect ratio, distribution and orientation. Nanocellulose, a biodegradable filler material, is reported to increase the puncture strength by $117 \%$ while reduce the water vapor permeability by $26 \%$ (Khan et al. $2010)$ even with a very low level of filler loading $(0.25 \%)$. To improve the properties of starch films, nanocellulose having the Young's modulus as high as $134 \mathrm{GPa}$ is being tried by various research groups as nanofillers. In this work, we have prepared nanocellulose from microcrystalline cellulose (Beckham et al. 2010) by high pressure homogenization process and the resultant nanocellulose was evaluated as fillers in starch films with GA as dispersing agent.

\section{Materials and methods}

Preparation of starch-nanocellulose composites films

Nanocellulose was prepared from microcrystalline cellulose $\left(\right.$ Avicel $^{\mathrm{TM}}$; average size of $50 \mu \mathrm{m}$ ) by high pressure homogenization process using pneumatic EmulsiFlex-C3 cell homogenizer (Avestin ${ }^{\mathrm{TM}}$ ) operated at 1,500 bar $(21,756 \mathrm{psi})$ pressure for 20 passes. Since single pass was not enough to reduce the size to nano range, multiple passes were required to reduce the particle size. The particle size reduction was monitored by visual observation of settling/suspension characteristics and by dynamic light scattering (DLS) particle size analyzer (Brookhaven 90Plus ${ }^{\circledR}$ ). The soluble starch derived from the potato starch by acid hydrolysis to a consistent molecular weight is supplied by Merck ${ }^{\circledR}$ Chemicals, India. The film forming solution was prepared by gelatinizing the soluble starch $(4.0 \%)$ at $95^{\circ} \mathrm{C}$ followed by addition of $0.02 \%$ sodium azide and $0.5 \%$ glycerol as antimicrobial and plasticizing agents, respectively. Films were formed by solution-casting process on Teflon plates and kept at $50^{\circ} \mathrm{C}$ overnight for drying. For nanocomposites, $1 \%$ (w/w of starch) nanocellulose and $1 \%$ (w/w of starch) GA were added and stirred well before casting.

Characterization of starch-nanocellulose composites

For polarized light microscopy, the starch films were observed under Nikon ${ }^{\circledR}$ inverted microscope. Images were collected with a color CCD camera. The atomic force microscope (AFM; Digital Instruments, model Dimen$\operatorname{sion}^{\mathrm{TM}} 3100$ ) was used in tapping mode to characterize the surface topography of the starch films. The silicon nitride cantilever tip was used for imaging. All the images were acquired under tapping mode with no software corrections. The contact angles for the starch films with water, glycerol, polyethylene glycol (PEG 200), 1-octanol and $N$, $N$-dimethyl formamide were analyzed using VCA Optima ${ }^{\circledR}$ analyzer. The Zisman plot method was used to calculate the surface energy of the films from the contact angle data.

The solubility percentage $(S \%)$ of the film was measured according to Romero-Bastida et al. 2005. The film strip $(40 \times 20 \mathrm{~mm})$ was dried to constant weight at $40^{\circ} \mathrm{C}$ in a vacuum oven and its initial weight $\left(M_{\mathrm{o}}\right)$ was taken. The weight sample was immersed in $50 \mathrm{ml}$ of water and kept for $24 \mathrm{~h}$ at $25^{\circ} \mathrm{C}$. The sample was taken out and again dried to constant weight $(M)$. The $S \%$ is calculated as follows:

$S \%=100 \times\left(M_{o}-M\right) / M_{o}$

The water vapor transmission rate (WVTR; $\mathrm{g} / \mathrm{m}^{2} \mathrm{~h}$ ) of films was analyzed according to the modified ASTM Method E 96-95 described by Gennadios et al. 1996. Circular test cups made of poly methylmethacrylate with $3.0 \mathrm{~cm}$ internal diameter and $2.0 \mathrm{~cm}$ height containing $10 \mathrm{ml}$ distilled water were sealed with the test specimen (starch films) using $\mathrm{O}$ rings. These cups were kept in the environmental chamber regulated at $25^{\circ} \mathrm{C}$ and $50 \% \mathrm{RH}$ and the weight was recorded every hour till $6 \mathrm{~h}$. The WVTR $\left(\mathrm{g} / \mathrm{m}^{2} \mathrm{~h}\right)$ was calculated as the slope of the regression line drawn using time in $X$ axis and weight in $Y$ axis. FTIR spectra of film samples were analyzed using the Thermal Nicolet Nexus 670 FT-IR spectrometer (Thermo Fisher Scientific Inc., Waltham, MA) under ambient conditions using the Smart MIRacle Accessory ${ }^{\mathrm{TM}}$. Each spectrum was averaged over 256 scans with $4 \mathrm{~cm}^{-1}$ resolution. The mechanical properties, tensile strength and percent elongation at break were analyzed using TAXT2iHR Texture Analyzer (Stable Micro Systems, NY, USA) according to ASTM standard method D882-91. The test specimens were cut into pieces of $40 \times 10 \mathrm{~mm}$ and conditioned at $50 \% \mathrm{RH}$ and $25^{\circ} \mathrm{C}$ for $48 \mathrm{~h}$. The thickness of the samples was measured using an electronic micrometer before analysis. Initial grip separation was 
$15 \mathrm{~mm}$ and cross-head speed was $5 \mathrm{~mm} / \mathrm{min}$. Ten specimens were analyzed for each sample and their average is reported. The tensile strength was calculated by dividing the maximum force exerted on the film during fracture by the cross-sectional area. Percent elongation at break was expressed as percentage of change of the original length of a specimen between grips at break.

\section{Results and discussion}

To overcome the strength and permeability problems of biodegradable starch film, montmorillonite (Kampeerapappun et al. 2007), nanocellulose (Lu et al. 2006) and nano-silica (Xiong et al. 2008) are being tried as fillers; however, the reduction on elongation at break was unavoidable due to aggregation of fillers and poor compatibility between fillers and matrix. In this work, GA was tried as dispersing agents to disperse nanocellulose (size: $392 \pm 36 \mathrm{~nm}$ ) uniformly in starch film. Glycerol is used as plasticizer in the preparation of starch film (Mali et al. 2005b). Sodium azide was used as an antimicrobial agent in the composite films. The polarized light microscopy was used to analyze the distribution of nanocellulose within the
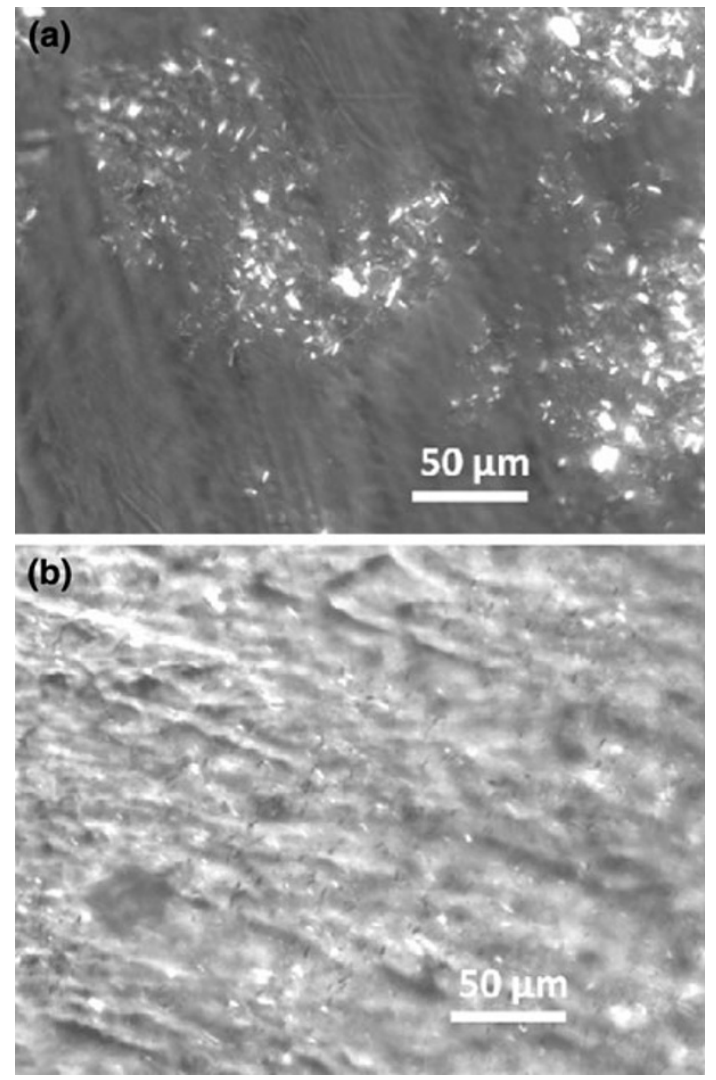

Fig. 1 Polarized optical micrographs of starch + nanocellulose film (a) and starch + nanocellulose [dispersed by GA] film (b) starch film. Since the size of nanocellulose is very less for its visualization under optical microscope, their optical activity was used for observation in polarized light. The whisker-shaped nanocellulose is optically active and when it aligns parallel with polarized light source, it appears bright and vice versa. In case of starch film impregnated with nanocellulose (without GA), aggregation of fillers was noted (Fig. 1). In case of GA dispersed nanocellulose, the uniform distribution of nanocellulose could be seen.

AFM analysis was carried out to understand the surface roughness of both control starch film and the starch film impregnated with nanocellulose dispersed by GA (Fig. 2). The control starch film had smooth surface showing globular structure of starch granules while that of nanocellulose impregnated starch film had network like rough surface due to the presence of nanocellulose whiskers. Moreover, the arrangement of nanocellulose whiskers is found to be in both directions, perpendicular to each other

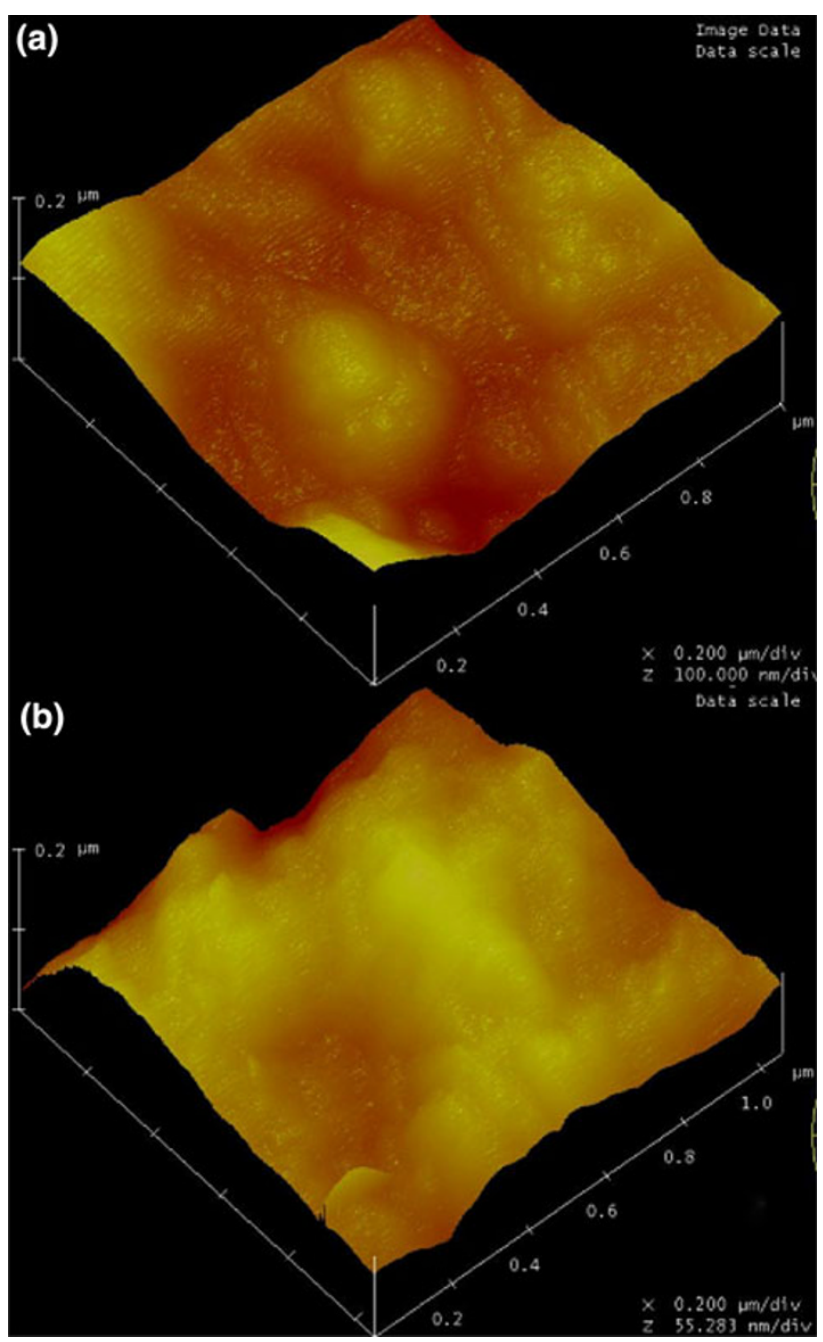

Fig. 2 AFM height images in tapping mode of starch film (a) and starch + nanocellulose [dispersed by GA] film (b)

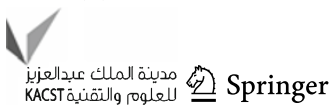


Table 1 Water vapor transmission rate (WVTR), surface energy, solubility and mechanical properties of starch film and its nanocomposites ${ }^{\mathrm{a}}$

\begin{tabular}{lllllrr}
\hline Starch films & $\begin{array}{l}\text { Surface energy } \\
(\text { dyne/cm })\end{array}$ & $\begin{array}{l}\text { Solubility } \\
(\%)\end{array}$ & $\begin{array}{l}\text { WVTR } \\
\left(\mathrm{g} / \mathrm{m}^{2} \mathrm{~h}^{1}\right)\end{array}$ & $\begin{array}{l}\text { Thickness } \\
(\mu \mathrm{m})\end{array}$ & $\begin{array}{l}\text { Tensile strength } \\
(\mathrm{MPa})\end{array}$ & $\begin{array}{l}\text { Elongation at } \\
\text { break }(\%)\end{array}$ \\
\hline Virgin starch film & $40.5 \pm 2.5$ & $39.5 \pm 0.5$ & $388 \pm 15$ & $140 \pm 2$ & $1.35 \pm 0.8$ & $20.2 \pm 2.5$ \\
Starch + nanocellulose film & $28.7 \pm 2.3$ & $35.7 \pm 1.7$ & $265 \pm 13$ & $150 \pm 2$ & $3.27 \pm 1.1$ & $22.8 \pm 2.9$ \\
Starch + nanocellulose dispersed by GA & $21.2 \pm 2.2$ & $32.1 \pm 0.5$ & $181 \pm 10$ & $150 \pm 2$ & $4.79 \pm 1.3$ & $36.6 \pm 3.8$ \\
\hline
\end{tabular}

${ }^{a}$ Reported values are mean $\pm \mathrm{SD}$ of ten replicates

Fig. 3 Effect of nanofillers and traditional fillers (micron sized) on the permeability behavior. Nanofillers (left) introduced the torturous path to the flow of water vapor while micron-sized fillers facilitate easy flow behavior
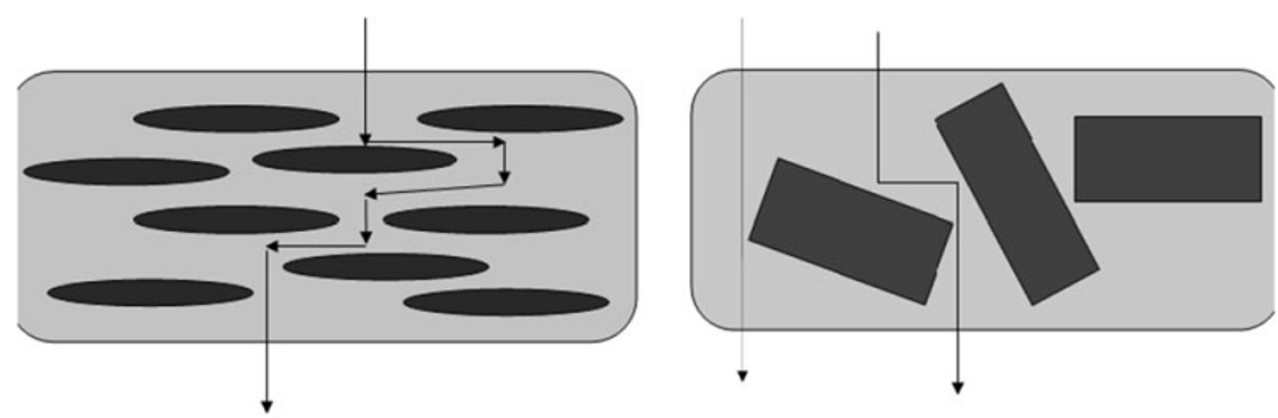

and supported by polarized optical micrographs. This arrangement may contribute to isotropic behavior in case of strength analysis.

The surface energy of pure starch film was analyzed to be 40.5 dyne/cm while that of starch impregnated nanocellulose film was $28.7 \mathrm{dyne} / \mathrm{cm}$ and of starch + nanocellulose dispersed by GA was 21.2 dyne/cm (Table 1). The drastic reduction in the surface energy of nanocomposites can be attributed to the addition of hydrophilic polymer like GA in the film and also due to the increased surface roughness, as demonstrated by AFM analysis.

The percent solubility of pure starch film (Table 1) was 39.5 while that of nanocellulose impregnated film had only 35.7. This reduction could be attributed to the addition of nanocellulose fillers as they are not soluble in water. Though the nanocellulose was added at a concentration of $1 \%$, an average of $4 \%$ reduction in solubility was noticed due to the inter-surface interaction of nanocellulose and starch. Moreover, the addition of GA has reduced the solubility further down to $32 \%$ by increasing the interaction between the nanofillers (nanocellulose) and the matrix (soluble starch). WVTR is very critical for any films to be used in agricultural field mulching operations. Pure starch film was found to have WVTR of $388 \mathrm{~g} / \mathrm{m}^{2} \mathrm{~h}$ (Table 1). The addition of nanocellulose has drastically reduced the WVTR down to $265 \mathrm{~g} / \mathrm{m}^{2} \mathrm{~h}$. The phenomenon behind this can be explained with the help of Fig. 3. The nanofillers, by its uniform distribution through out the starch matrix restrict the transmission of water vapor. The transmission of water vapor through starch film will be a torturous path leading to reduced rate of transmission.

In FTIR analysis (Fig. 4), since the chemical nature of starch and cellulose is mostly similar, many of the

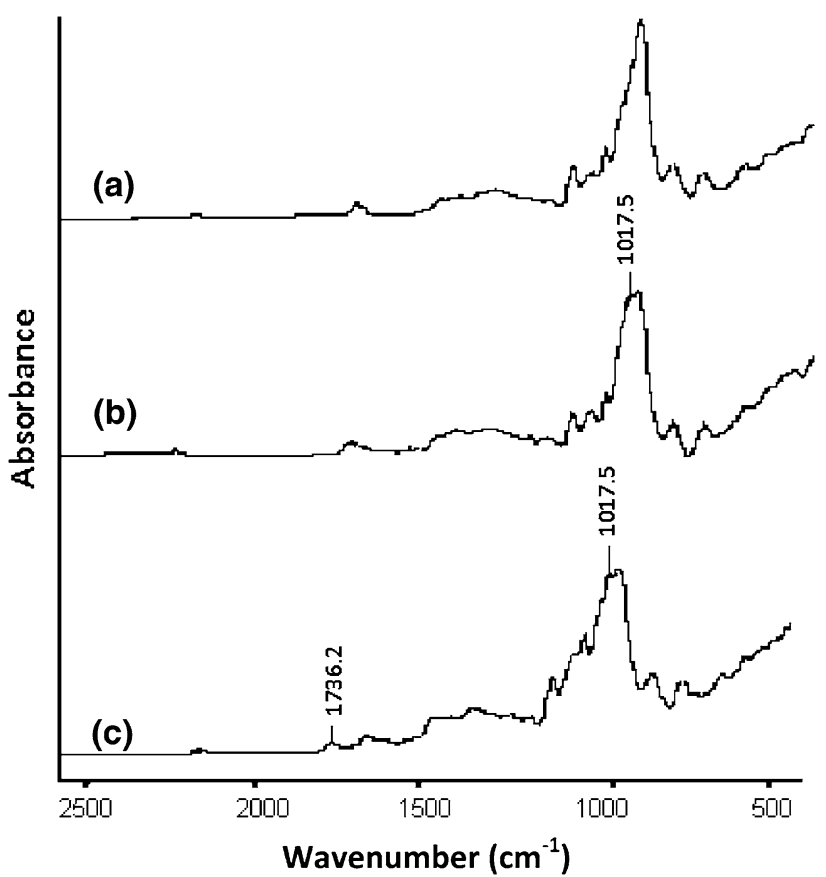

Fig. 4 FTIR spectra of pure starch film (a), starch + nanocellulose film (b) and starch + nanocellulose [dispersed by gum arabic] film (c)

characteristic peaks overlap and hence distinction is difficult. The characteristic peaks for cellulose (Oh et al. 2005; Satyamurthy et al. 2011) are the hydrogen-bonded stretching at $3,299 \mathrm{~cm}^{-1}$, the $\mathrm{OH}$ bending of the adsorbed water at $1,644 \mathrm{~cm}^{-1}$, the $\mathrm{CH}$ stretching at $2,921 \mathrm{~cm}^{-1}$, the $\mathrm{HCH}$ and $\mathrm{OCH}$ in-plane bending vibrations at $1,430 \mathrm{~cm}^{-1}$, the $\mathrm{CH}$ deformation vibration at $1,373 \mathrm{~cm}^{-1}$, the $\mathrm{COC}$, $\mathrm{CCO}$, and $\mathrm{CCH}$ deformation modes and stretching 
vibrations in which the motions of the $\mathrm{C}-5$ and $\mathrm{C}-6$ atoms are at $850 \mathrm{~cm}^{-1}$, and the $\mathrm{C}-\mathrm{OH}$ out-of-plane bending mode around $670 \mathrm{~cm}^{-1}$. These characteristics peaks for nanocellulose overlap with that of starch and hence a clear distinction was not observed. Only a distinct peak was observed at $1,017 \mathrm{~cm}^{-1}$ in case of nanocellulose impregnated starch film that could be attributed to the $\gamma \mathrm{CO}$ at C-3. $\gamma \mathrm{C}-\mathrm{C}$ (Kacuráková et al. 2002; Liang and Marchessault 1959). In case of GA stabilized nanocomposite films, a distinct peak was observed at $1,736 \mathrm{~cm}^{-1}$ that could be attributed to the symmetric stretching of carbonyl group.

The mechanical properties of various starch films was analyzed and given in Table 1 . There is a marginal increase in the thickness of the nanocomposite films than that of pure starch film due to the addition of nanocellulose as fillers. The tensile strength of pure starch film was 1.35 MPa which is insufficient for food packaging applications. When the nanocellulose is added as fillers, the tensile strength has been increased to 3.27 MPa. Further, the addition of GA enhanced their mechanical strength to 4.79 $\mathrm{MPa}$ due to their support in uniform distribution of nanocellulose, resulting in a uniform stress distribution behavior. In addition, the elongation at break increased significantly due to the addition of GA that suggests the role of GA as plasticizing agent. In an earlier study (Kumar and Singh 2008), photo-cross linking of the starch matrix using sodium benzoate as photo-sensitizer was reported to improve the physical and mechanical properties when MCC was used as filler. Since they have used MCC as fillers, they had to use $10-15 \%(\mathrm{w} / \mathrm{w})$ of starch matrix; while we have used only $1 \%(\mathrm{w} / \mathrm{w})$ of nanocellulose to achieve the same result. This supports the advantage in using nanofillers compared to that of micron-sized fillers.

\section{Conclusions}

To cope up with the limitation of petroleum supply and environmental pollution concern, biopolymers like starch are being explored for use in packaging industries. Due to perfect crystalline nature of nanocellulose, they have high modulus and will potentially act as efficient reinforcing agent. Apart from improving the mechanical properties, nanocellulose as fillers reduces water vapor permeability of the starch matrix. To harvest the full potential of nanofillers, in the present work, GA was evaluated as a dispersing agent. Use of GA helped to reduce the surface energy of matrix thereby assists in uniform distribution of nanofillers through out the starch matrix. There is a significant improvement in the mechanical and barrier properties of starch-nanocellulose films prepared using GA as dispersing agent. Being completely biopolymer based, starchnanocellulose film will revolutionize the fields of food packaging, agricultural field mulching and healthcare sectors.

Acknowledgments The first author is thankful to Dr. A.J. Shaikh and Dr. S. Sreenivasan for their kind suggestions and support for this research work. This research was partly supported by the National Agricultural Innovation Project (NAIP), Indian Council of Agricultural Research (ICAR) through its sub-project entitled 'Synthesis and characterization of nanocellulose and its application in biodegradable polymer composites to enhance their performance', code number 'C2041'.

Open Access This article is distributed under the terms of the Creative Commons Attribution License which permits any use, distribution and reproduction in any medium, provided the original author(s) and source are credited.

\section{References}

Al-Assaf S, Sakata M, McKenna C, Aoki H, Phillips G (2009) Molecular associations in acacia gums. Struct Chem 20(2):325-336. doi:10.1007/s11224-009-9430-3

Arvanitoyannis IS (1999) Totally and partially biodegradable polymer blends based on natural and synthetic macromolecules: preparation, physical properties, and potential as food packaging materials. J Macromol Sci Rev Macromol Chem Phys C 39(2):205-271

Beckham GT, Bomble YJ, Matthews JF, Taylor CB, Resch MG, Yarbrough JM, Decker SR, Bu L, Zhao X, McCabe C, Wohlert J, Bergenstrahle M, Brady JW, Adney WS, Himmel ME, Crowley MF (2010) The $O$-glycosylated linker from the Trichoderma reesei Family 7 cellulase is a flexible, disordered protein. Biophys J 99(11):3773-3781. doi:10.1016/j.bpj.2010.10.032

Chen Y, Liu C, Chang PR, Cao X, Anderson DP (2009) Bionanocomposites based on pea starch and cellulose nanowhiskers hydrolyzed from pea hull fibre: effect of hydrolysis time. Carbohydr Polym 76(4):607-615. doi:10.1016/j.carbpol.2008.11.030

Dickinson E (2003) Hydrocolloids at interfaces and the influence on the properties of dispersed systems. Food Hydrocolloids 17(1):25-39. doi:10.1016/s0268-005x(01)00120-5

French D (1984) Organization of starch granules. In: Whistler RL, BeMiller JN, Paschall EF (eds) Starch: chemistry and technology. Academic Press Inc, London, pp 183-247

Gennadios A, Ghorpade VM, Weller CL, Hanna MA (1996) Heat curing of soy protein films. Trans ASABE 39(2):575-579

Kacuráková M, Smith AC, Gidley MJ, Wilson RH (2002) Molecular interactions in bacterial cellulose composites studied by 1D FT-IR and dynamic 2D FT-IR spectroscopy. Carbohydr Res 337(12):1145-1153. doi:10.1016/s0008-6215(02)00102-7

Kampeerapappun P, Aht-ong D, Pentrakoon D, Srikulkit K (2007) Preparation of cassava starch/montmorillonite composite film. Carbohydr Polym 67(2):155-163. doi:10.1016/j.carbpol.2006. 05.012

Kannan R, Rahing V, Cutler C, Pandrapragada R, Katti KK, Kattumuri V, Robertson JD, Casteel SJ, Jurisson S, Smith C, Boote E, Katti KV (2006) Nanocompatible chemistry toward fabrication of target-specific gold nanoparticles. J Am Chem Soc 128(35):11342-11343. doi:10.1021/ja063280c

Khan RA, Salmieri S, Dussault D, Uribe-Calderon J, Kamal MR, Safrany A, Lacroix M (2010) Production and properties of nanocellulose-reinforced methylcellulose-based biodegradable films. J Agric Food Chem 58(13):7878-7885. doi:10.1021/ jf1006853 
Kumar AP, Singh RP (2008) Biocomposites of cellulose reinforced starch: improvement of properties by photo-induced crosslinking. Bioresour Technol 99(18):8803-8809. doi:10.1016/j.bior tech.2008.04.045

Liang CY, Marchessault RH (1959) Infrared spectra of crystalline polysaccharides. II. Native celluloses in the region from 640 to $1700 \mathrm{~cm}^{-1}$. J Polymer Sci 39(135):269-278. doi:10.1002/pol. 1959.1203913521

Lu Y, Weng L, Cao X (2006) Morphological, thermal and mechanical properties of ramie crystallites-reinforced plasticized starch biocomposites. Carbohydr Polym 63(2):198-204. doi:10.1016/ j.carbpol.2005.08.027

Mali S, Grossmann MVE, GarcIa MA, Martino MN, Zaritzky NE (2005a) Mechanical and thermal properties of yam starch films. Food Hydrocoll 19(1):157-164. doi:10.1016/j.foodhyd.2004. 05.002

Mali S, Sakanaka LS, Yamashita F, Grossmann MVE (2005b) Water sorption and mechanical properties of cassava starch films and their relation to plasticizing effect. Carbohydr Polym 60(3): 283-289. doi:10.1016/j.carbpol.2005.01.003

Oh SY, Yoo DI, Shin Y, Seo G (2005) FTIR analysis of cellulose treated with sodium hydroxide and carbon dioxide. Carbohydr Res 340(3):417-428. doi:10.1016/j.carres.2004.11.027

Roman M, Winter WT (2004) Effect of sulfate groups from sulfuric acid hydrolysis on the thermal degradation behavior of bacterial cellulose. Biomacromolecules 5(5):1671-1677. doi:10.1021/ bm034519+

Romero-Bastida CA, Bello-Pérez LA, García MA, Martino MN, Solorza-Feria J, Zaritzky NE (2005) Physicochemical and microstructural characterization of films prepared by thermal and cold gelatinization from non-conventional sources of starches. Carbohydr Polym 60(2):235-244. doi:10.1016/j.carb pol.2005.01.004

Roque ACA, Bicho A, Batalha IL, Cardoso AS, Hussain A (2009) Biocompatible and bioactive gum arabic coated iron oxide magnetic nanoparticles. J Biotechnol 144(4):313-320. doi: 10.1016/j.jbiotec.2009.08.020

Satyamurthy P, Jain P, Balasubramanya RH, Vigneshwaran N (2011) Preparation and characterization of cellulose nanowhiskers from cotton fibres by controlled microbial hydrolysis. Carbohydr Polym 83(1):122-129. doi:10.1016/j.carbpol.2010.07.029

Teixeira EdM, Pasquini D, Curvelo AAS, Corradini E, Belgacem MN, Dufresne A (2009) Cassava bagasse cellulose nanofibrils reinforced thermoplastic cassava starch. Carbohydrate Polymers 78(3):422-431. doi:10.1016/j.carbpol.2009.04.034

Wenjuan Z (2011) Study on nanocellulose/starch composites. Adv Mater Res 187:544-547

Xiong H, Tang S, Tang H, Zou P (2008) The structure and properties of a starch-based biodegradable film. Carbohydr Polym 71(2): 263-268. doi:10.1016/j.carbpol.2007.05.035 